\title{
“You can't always get what you want...": economic thinking, constrained optimization and health professions education
}

\author{
J. A. Cleland ${ }^{1}$ (D) . J. Foo $^{2} \cdot$ D. Ilic ${ }^{3}$ S. Maloney ${ }^{2} \cdot$ Y. You $^{4}$
}

Received: 30 June 2020 / Accepted: 21 October 2020 / Published online: 3 November 2020

(c) Springer Nature B.V. 2020

\begin{abstract}
Every choice we make in health professions education has a cost, whether it be financial or otherwise; by choosing one action (e.g., integrating more simulation, studying more for a summative examination) we lose the opportunity to take an alternative action (e.g., freeing up time for other teaching, leisure time). Economics significantly shapes the way we behave and think as educators and learners and so there is increasing interest in using economic ways of thinking and approaches to examine and understand how choices are made, the influence of constraints and boundaries in educational decision making, and how costs are felt. Thus, in this article, we provide a brief historical overview of modern economics, to illustrate how the core concepts of economics - scarcity (and desirability), rationality, and optimization-developed over time. We explain the important concept of bounded rationality, which explains how individual, meso-factors and contextual factors influence decision making. We then consider the opportunities that these concepts afford for health professions education and research. We conclude by proposing that embracing economic thinking opens up new questions and new ways of approaching old questions which can add knowledge about how choice is enacted in contemporary health professions education.
\end{abstract}

Keywords Economics $\cdot$ Health professions education $\cdot$ Optimization $\cdot$ Scarcity $\cdot$ Rationality

J. A. Cleland

Jennifer.cleland@ntu.edu.sg

1 Lee Kong Chian School of Medicine, Nanyang Technological University, Singapore 308232, Singapore

2 School of Primary and Allied Health Care, Faculty of Medicine, Nursing and Health Sciences, Monash University, Melbourne, Australia

3 Medical Education Research and Quality (MERQ) Unit, School of Public Health and Preventive Medicine, Monash University, Melbourne, Australia

4 Health Science Centre, Peking University, Beijing, China 


\section{Introduction}

Consider some of the choices facing health professions educators. Should we give our students more feedback? More or less simulation? Expand the number of stations in an objective structured clinical examination (OSCE)? Giving more feedback probably requires more faculty time and training, which might mean less faculty time for something else. More simulation may be desirable in terms of mastering skills but which activity should it replace, and can the simulated patients, rooms and other resources be feasibly sourced? More OSCE stations might increase reliability and curriculum coverage but will require more examiners, more questions and more preparatory and examination time.

Not only must we make choices as faculty, so too do students and the greater society. A student may choose not to study for a formative assessment to focus their time on preparing for summative examinations. As a society, we may want fair access to medicine, so that medical students represent all groups in society as well as excelling in terms of academic and personal qualities. Both aspects may be desirable, but attaining excellent pre-entry qualifications may conflict with those aspects and therefore require trade-off with expanding the diversity of the medical student body (see later for further discussion).

In short, every choice we make has a cost, whether they be financial or otherwise; by choosing one action we lose the opportunity to take an alternative action; and these opportunity costs may be felt in different ways by different individuals, groups and society.

Choice is a focus of study in many different fields. In this article, we introduce thinking about choice from the economic perspective (Johnes 1993). Although there is no single definition of economics, this description is helpful in understanding its nature and scope: "Economists study how individuals, organizations, and societies employ time, money, and effort. Economics provides a framework for understanding the behavior of individuals and organizations as they generate and allocate human, material, and financial resources." (Brewer et al. 2010, p. 193). In short, economic thinking allows us to examine, understand and reflect on how individuals, groups and societies choose among the alternatives available to them.

It is timely to step back and consider some of the key concepts in economics and how these can be applied to health professions education (HPE). First, there seems an appetite in the literature to rigorously evaluate and optimise allocation of medical education resources (Foo et al. 2019; Maloney et al. 2019), and to apply economic methodologies which could be used to address HPE questions (e.g., Cleland et al. 2018b). Second, in a recent commentary about strategic planning during COVID-19, Tolsgaard et al. (2020) stated that the "choices that we make now for how to use our workforce, which education and training activities to stop, continue or modify, will [also] have profound workforce consequences and implications for quality of non-COVID-19 areas of clinical care". This commentary alluded to the role of constraints and boundaries in decision making but did not expand on their nature. Without this granularity, medical education decision makers do not have the necessary building blocks to consider their decision making, the ramifications of decisions or insight into creative ways to solve everyday HPE problems. Third, longstanding increases in medical education costs and student debt (AAMC 2017), combined with more recent COVID-19 related pressures on institutional budgets (Burki 2020), has led to pressures to optimise medical education while 
continuing to generate value for all involved. The concept of value is also of interest in respect to value to whom? Economics provides language and frameworks for considering this and other tensions-opening up new and creative ways of thinking and illuminating the implications of actions at the level of individuals, groups and institutions in HPE.

To set the scene, we provide a brief historical overview of modern economics. In Table 1 we give a very brief overview of key time periods, figures, theories and concepts in economics. For more details we direct readers to key economics primers (e.g., Backhouse and Tribe 2018). We then explain the core concepts of economics: scarcity (and desirability), rationality, and optimization (Table 2). We then consider the opportunities that these concepts afford for health professions education and research.

\section{A (very) brief history of economics: classical theory to bounded rationality}

\section{Classical economics}

Economic ideas have been present since antiquity. However, modern economic thought was laid down during the Scientific Revolution (16th-18th century) (Backhouse 2002). Adam Smith, with debts to his predecessors and contemporaries, is regarded as the father of classical/classical political economics via his book, The Wealth of Nations, which was first published in 1776 (note that Smith was also a philosopher but in this article we focus on his contribution to economics). Classical economists such as Adam Smith and Karl Marx regarded economy as a part of broader social, political, historical and institutional domain and discussed economic process within this context (e.g., Meek 1977; Skinner 2003). Within this framework, classical economic doctrine asserts that the value of a good (how much of another good or service it exchanges for in the market) is proportional to how much labour was required to produce it, including the labour required to produce the raw materials and machinery used in the process. A second core assertion is that the power of the market system, if left alone (i.e., without government intervention), will ensure full employment and usage of economic resources. Within this natural order (as proposed by John Locke in his Second Treatise of Government in 1689), there may be occasional deviation, but individual self-interest based on the information required for rationale decision making, supply and demand, preferences and constraints (e.g., laws, religion, customs), and social order (what Smith referred to as the "invisible hand": Smith 1776, p. 184) will underpin economic self-regulation.

\section{Neoclassical economics}

In the 250 years following Smith's Wealth of Nations, the world changed, and economic theories also evolved as generations of economists tried to understand and explain economic phenomenon in changing times and societies. Classical or political economics as a field then made a transition to neoclassical economics which still assumed that the market and the "invisible hand" will ensure the optimal allocation of resources. However, the basic determinant of economic decisions became individual choice and maximizing behavior, the optimal utilization of scarce resources to satisfy the needs and desires of individual 


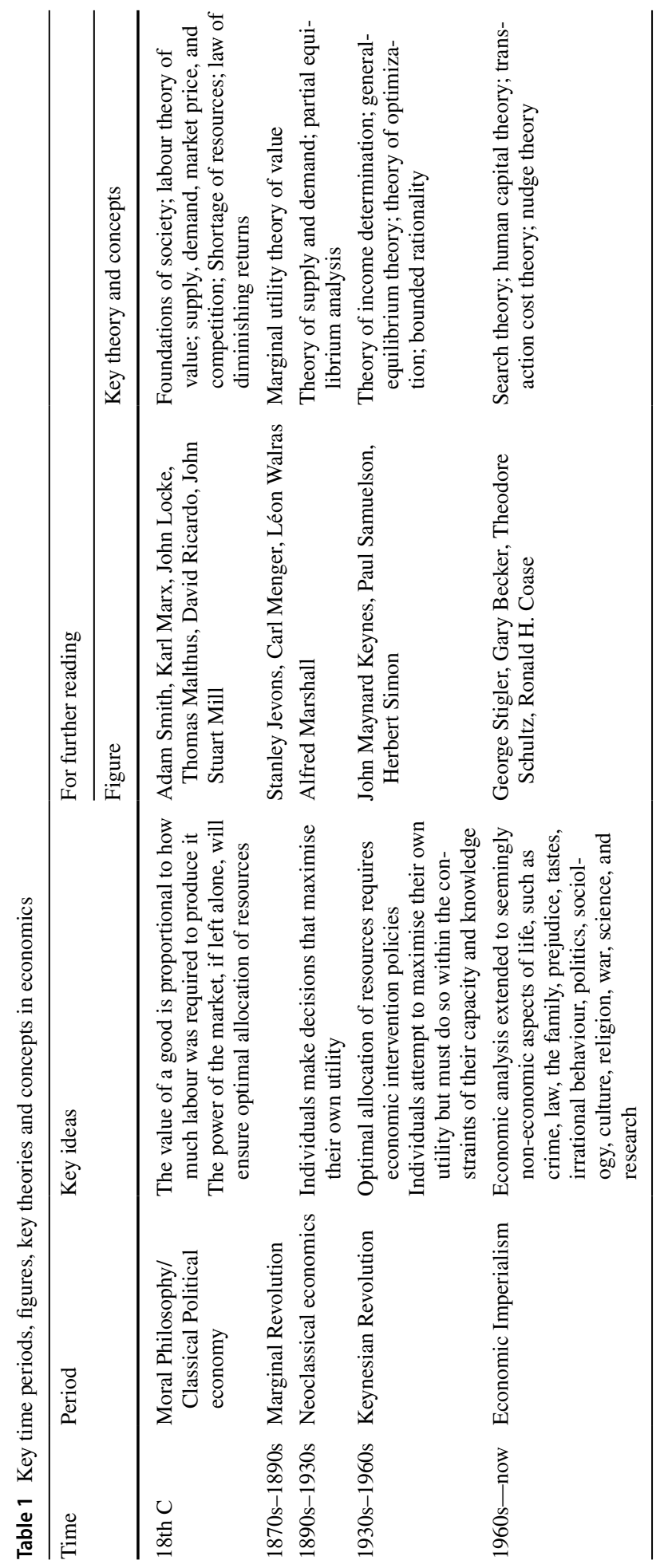


Table 2 Core economics principles_-bounded rationality, scarcity and optimization/satisficing

\begin{tabular}{|c|c|}
\hline Bounded rationality & $\begin{array}{l}\text { Rationality is limited when individuals make decisions: by the tractability of the } \\
\text { decision problem, the cognitive limitations of the mind, and the time available } \\
\text { to make the decision, and so on } \\
\text { Bounded rationality is the idea that we make decisions that are rational, but } \\
\text { within the limits of the information available to us and our mental capabilities }\end{array}$ \\
\hline Scarcity & $\begin{array}{l}\text { Due to limited resources and infinite demands, society needs to determine how to } \\
\text { produce and distribute these relatively scarce resources. As a result of scarcity } \\
\text { of resources, economic thinking considers opportunity cost-having to make } \\
\text { choices between two or more options. For example, investing in donor dissec- } \\
\text { tion for anatomy education, leaving less time and finances to invest in virtual } \\
\text { reality anatomy education }\end{array}$ \\
\hline Optimization/satisficing & $\begin{array}{l}\text { Optimization refers to getting the best deal/outcome possible within resource } \\
\text { constraints. Satisficing is a decision-making strategy that aims for a satisfactory } \\
\text { or adequate result, rather than the optimal solution. It refers to taking a "good } \\
\text { enough" decision which requires lesser resources, compared to committing } \\
\text { greater resources (effort, costs and time) to find the best possible decision }\end{array}$ \\
\hline
\end{tabular}

agents, not social processes within a specific social system (e.g., De Vroey 1975). The term "Marginalist Revolution" is commonly used to indicate this change of direction in economic science, with its shift to a subjective theory of value (Roncaglia 2005, p. 278). However, as per Smith's classical model, neoclassical economics assumed that everyone has free access to the information they require for decision making, enabling rational decision making in terms of choosing between identifiable outcomes and associated with values (e.g., firms will make choices which will maximize profits, individuals will make choices which maximize personal benefit or satisfaction).

\section{Keynesian economics}

Moving forwards in time, in 1930s, in the time of the Great Depression, John Maynard Keynes was highly critical of classical economic arguments that natural economic forces and incentives would be sufficient to help the economy recover. Instead, Keynes advocated for increased government expenditures and lower taxes to stimulate demand and pull the global economy out of the depression. Subsequently, Keynesian economics was used to refer to the concept that optimal economic performance could be achieved by influencing choice through economic intervention policies by the government. It was at this point in time that the separate disciplines of micro- and macro-economics first emerged, with the recognition that supply and demand at the level of individual markets was not sufficient to explain (macro-) factors such as inflation, market failures such as the Great Depression and unemployment. In macro-economics, the government and, increasingly, global markets are the object of analysis.

As with those before him, Keynes (1921) argued that people make economic decisions on essentially rational grounds, using all the information available to them to form accurate probabilities about the world. However, as time progressed Keynes' position shifted to apparently question this central tenet of economics, that actors are fundamentally rational. His view was that people often lack sufficient information and face too much uncertainty to calculate probabilities and make rationale choices in any meaningful way. Instead, they filter information using less than reliable practices, including assuming that the present is the best available predictor of the future and looking to those around them/social convention 
(1936). Neither of these practices are efficient, optimal or stable but they are not entirely unreasonable if there is no other information that instructs otherwise, and one is short of time and/or analytical/cognitive capability. Keynes states "human decisions... cannot depend on strict mathematical expectations, since the basis for making such calculations does not exist... "Our rational selves [choose] between the alternatives as best we are able, calculating where we can." Failing those instances, however, decisions are necessarily left open to "whim or sentiment or chance" (Keynes 1936, p. 162).

This is an important shift and led to the concept of bounded rationality-rationality taking place within operational constraints (Simon 1955). Bounded rationality is not the same as irrationality: decision-makers are still attempting to make as rational a decision as possible given the information, time and capability to store and utilize information available to them. Bounded rationality explains situations where people do not take the action that would maximize results (from an economic point of view), because they do not have all the information needed to make a truly rational choice. Bounded rationality also acknowledges that individual and meso- factors-such as embedded values and personal preferences, limited feedback and tendencies to avoid discomfort, as well as exogenous factors such as the environment in which the individual inhabits-influence decision making (e.g., Dawnay and Shah 2005; Thaler and Sunstein 2009; Dolan et al. 2010 Furubotn and Richter 2003).

Eagle-eyed readers and those with an interest in cognition will have noted the references to cognitive capacity and heuristics above. Although originating in economics, bounded rationality is now a very multi-disciplinary concept, and the basis of theories and studies in cognitive- and neuropsychology, biology, computer science, and philosophy. These perspectives all add to current understanding (for further information, we direct readers to https://plato.stanford.edu/entries/bounded-rationality/\#BettBoun).

\section{Selecting among alternatives}

As stated earlier, selecting among alternatives involves considering scarcity (including supply and demand) and optimization, as well as (bounded) rationality (Mankiw 2011). In almost every situation, resources are limited, or perceived to be limited, and you have to give up something to get something else (opportunity cost again). For example, a 'free lunch' is not really free, as to consume the meal, a person has to forgo opportunities that could be taken to engage in other activities (e.g., work, nap, exercise), even if he/she doesn't have to pay the bill for the lunch. In HPE, an example of scarcity might be investing in dissection for anatomy education, leaving less time and finances to invest in virtual reality anatomy education. Other examples might be employing/allocating staff for one part of the curriculum meaning no, or less resource for another part of the curriculum, or removing sessional teachers and replacing them with tenured research staff who are contractually obliged to teach, thus reducing costs but possibly also compromising quality and the student learning experience.

Economists view decision-making behaviour according to the basic principle that people make decisions by comparing perceived benefits with costs, to get the best deal/ outcome possible within resource constraints (optimization). An example of this at the individual level might be the best use of time (a limited resource) in the run up to examinations. For a student, the benefit of gaining an extra couple of hours of study might be the best use of time and worth the cost of missing rugby training. In medical education, faculty may ask whether greater benefits can be found by incurring greater costs (e.g., shifting 
from large-group to smaller group teaching with the resultant costs in terms of more educators and more time but potential gains in terms of student learning and thus potential savings from less remediation and attrition); whether the gains from substituting group feedback for individual feedback would be worth the cost of changing systems and a potential drop in student satisfaction. Because bounded rationality thinking is limited by factors such as the available information, the nature of the problem, cognitive and time limits, the goal posts and language have shifted to acknowledging that economic decision making is usually about doing the best you can with what you have. This formulation of boundedly rational decision making as a constrained optimization problem is commonplace in economics (Arrow 2004), and is labelled "satisficing," (a combination of satisfy and suffice, coined by Simon 1957).

\section{Economic thinking applied to HPE}

Economic thinking, with its core principles of (bounded) rationality, scarcity and optimization/satisficing (see Table 2), provides a novel lens to understand the behaviours (choices) of organisations, groups and individuals in HPE, one which can encourage different ways of thinking, and open new avenues for thought and exploration. Note however, that while borrowing from other disciplines is not new in HPE (e.g., Varpio et al. 2015), it is critical to carefully consider theories and concepts, and check their assumptions are congruent with the specific research question (Murray and Evers 1989).

We suggest some outstanding research questions and topics that could be addressed using economic concepts and thinking below. Our unit of analysis is micro-economicsthe level of the individual, group and organisation. We acknowledge that there are macroeconomic factors that are very relevant to HPE (e.g., Walsh 2014), such as the number of medical and other healthcare students trained and government policy on different aspects of HPE. However, our focus and examples reflect our own interests and observations, and mostly relate to bounded rationality and optimization. They are by no means exhaustive but refer to day-to-day activities and tensions which will be familiar to educators across the globe. We also direct readers to two recent papers, one which sets out how to read economics studies (Maloney et al. 2019) and the second which provides guidance on how to conduct cost and value analyses in HPE (Foo et al., in press).

Our first example is that of bounded rationality. In many contexts and institutions students are asked to rate their satisfaction with their course/aspects of their course. Aggregate responses or ratings of this data are used as quality "signals" or performance indicators and used by different people for different purposes. For example, potential applicants may use these satisfaction rankings to help them decide where to study (e.g., Horstchraer 2012), governments may use them as indicators of institutional performance and management [and link them to funding; e.g., McCormack et al. 2014)] and institutions may use them for performance review. However, student responses to such surveys are bounded by their lack of experience of other university education, scheduling and time available to them to fill in feedback forms, ease of completing such evaluations, the importance they give to filling in such forms, how interested they are in their course, current standing in the course (e.g. first year or final year), academic performance in the course and whether they "like" the teachers or not. They may also be influenced by the norms of student feedback in their institution. Is this mandatory? Do students take it seriously? Do they believe their views make any difference? Moreover, econometric analysis suggests that "teaching quality" factors 
such as student-staff ratios are associated with responses, but so too are extraneous factors such as whether or not students pay fees or not (raising expectations linked to education as needing to deliver value for money, or the commodification of education; e.g., BacherHicks, Chin, Kane and Staiger, 2019; Staddon and Standish 2012), or how likely they are to get a job after graduating (e.g., Lenton 2015). Or indeed whether they are offered cookies in class or not (Hassler et al. 2018)! Student satisfaction may be quantifiable, but it should not be relied upon given bounded rationality (e.g., Dawnay and Shah 2005; Thaler and Sunstein 2009; Dolan et al. 2010). Yet many institutions continue to use student satisfaction for different purposes. The concept of optimization is useful here. Student satisfaction is a simple and cheap outcome assessment (given the complexity of establishing a simple, valid multi-factorial evaluation strategy) which may be a "good enough" (satisficing) indicator, aligning with an organisational reference point in respect of performance/ quality management. In other words, organisations also are boundedly rational, situated within their own economic, social and historical contexts and norms (Nielsen and Moynihan 2017), and need to make judgements within resource constraints.

A second example of bounded rationality is that of medical careers decision making. Many studies report on the importance of exposure to specialities and different clinical environments for medical student career decision making. Not considering certain career options appears to relate to the lack of information or knowledge needed in terms of the various options, understanding one's self, motivation and "dysfunctional myths": all factors which reflect bounded rationality (e.g., Stamovlasis and Vaiopoulou 2017). An example of a dysfunctional myth, linked to lack of information and faulty heuristics, may be the assumption that rural training programs provide poorer educational outcomes than urban ones, or similarly placement at large teaching hospitals opens future employment opportunities compared to placement at smaller teaching hospitals. A well-advertised league table comparing successful completions or licencing exam scores across training programs, or any other credible source of information (Self 2009), may correct this assumption and support accurate decision-making on educational outcomes.

Medical careers decision making leads us into health workforce planning. The societallevel challenge for workforce planners is to ensure the right mix of health professions, specialities within professions, and geographical distribution to ensure the right capabilities are in the right place to meet the health needs of local populations. This is optimization of relatively scarce resources, particularly in countries with insufficient training capabilities. Economic theories can help to explain how medical students and residents/trainees make career choices (see earlier), as well as provide testable hypotheses and methodological approaches to inform interventions designed to encourage choice towards areas of need. Healthcare organisations seeking to attract residents/trainees can look to strengthen those aspects of the workplace for which evidence using economic approaches, such as discrete choice experiments, suggest are highly valued by the target group (e.g., good working conditions: e.g., Scanlan et al. 2018; Cleland et al. 2016, 2017). At the same time, and as above, organisations must also make sure that information about these positive changes are readily available to potential applicants so it can factor into their decision-making process.

Admissions is fundamentally an optimization process for medical schools: identifying and implementing processes which select the best applicants from the available pool at the same time as balancing political, social and academic drivers for admissions (e.g., Fielding et al. 2018; Cleland et al. 2018b). A recent review highlighted the need to consider not only the reliability and validity of admissions tools and processes, but also to bring fairness and cost-effectiveness into admissions research and decision making (e.g., Patterson et al. 2016). Several studies have done so (e.g., Hissbach et al. 2014; Rosenfeld et al. 2008; Schreurs 
et al. 2018; Tiller et al. 2013; Ziv et al. 2008) but this remains an underdeveloped area of admissions research. Admissions costs can be considered from different angles [e.g., of the institution or the individual applicant (e.g., Foo et al. 2020)]. Outcomes measures must assess value as well as cost (cheapest is not necessary best: see Scheurs et al. 2018), and look at individual-level outcomes for both distal (e.g., location and type of position postqualification) as well as proximal (e.g., performance in medical school) indicators.

Admissions can also be considered an optimization/satisficing process from a different angle. Places are scarce and admissions committees must consider the balance between the expected relative effort and benefit of using different selection criteria or processes to shift through more applicants than places. An admissions committee which takes the position that academic attainment is the most important factor in selection will likely invest relatively less resource into selecting for personal qualities than would an institution that places high value on the latter (Foo and Hay 2020). Looking at the mission statements of different medical schools can give some indication of what they value and their admissions priorities, and may explain differences in admissions processes, including how different components within an admissions process are weighed (see Table 3 ).

Our last point in respect to admissions is that of bounded rationality. Medical school selection committees are faced with an abundance of "traditional" applicants who, experience suggests, will be likely to progress and graduate in a satisfactory manner. "Nontraditional" applicants, while valued at a macro-level in respect of government policies to increase diversity, are more of an unknown quality and hence challenge the bounded rational decision-maker (better the devil you know), potentially jeopardising institutional reputation and metrics if they do not perform adequately. That medical schools and medicine are slow to change is not news (e.g., Whitehead 2011). However, economic concepts provide a novel lens by which to consider admissions decision making, and can inform the design and evaluation of change interventions so admissions aligns more with macrodrivers (e.g., governmental drivers to increase the diversity of the medical profession to meet changing societal needs).

Table 3 Comparing perceived benefits with costs-or where there is a will, there is a way

\begin{tabular}{|c|c|}
\hline Medical School A & Medical School B \\
\hline $\begin{array}{l}\text { Affluent } \\
\text { A mission "to equip doctors } \\
\text { who advance the science and } \\
\text { practice of medicine" }\end{array}$ & $\begin{array}{l}\text { Not-for-profit } \\
\text { A mission "to develop through } \\
\text { education and training, compas- } \\
\text { sionate, professionally excellent, } \\
\text { ethically sound individuals who } \\
\text { will go out as servant-leaders of } \\
\text { health teams and healing com- } \\
\text { munities" }\end{array}$ \\
\hline $\begin{array}{l}\text { Admissions } \\
\text { Academic attainment }+ \text { interna- } \\
\text { tional admissions test }+ \text { multi- } \\
\text { ple mini interview (MMI) } \\
\text { No widening access agenda }\end{array}$ & $\begin{array}{l}\text { Admissions } \\
\text { Much weigh put on community } \\
\text { recommendations } \\
\text { Quota system to ensure propor- } \\
\text { tionate regional representation, } \\
\text { and places for candidates from } \\
\text { disadvantaged communities } \\
\text { Academic attainment + interna- } \\
\text { tional admissions test }+3 \text {-day } \\
\text { residential selection centre } \\
\text { mapped to the mission and values } \\
\text { of the institution }\end{array}$ \\
\hline
\end{tabular}


Similar discussions are relevant to assessment. Van der Vleuten's utility formulae included cost effectiveness (van der Vleuten 1996). However, 25 years on this remains the most under-researched component of the utility framework, possibly because of anxiety about balancing change with maintaining standards. Only a few authors have reported on direct assessment costs (e.g., Brown et al. 2015) while others have looked directly at assessment approaches which reduce costs but maintain robust psychometric properties (e.g., Currie, Sivasubramaniam and Cleland 2016). Drawing on healthcare research practices (e.g., Halpern et al. 1998), economic modelling may help the HPE community measure and compare assessment activities with the necessary impact, scalability, and sustainability to optimize educational outcomes. Economic thinking also opens up assessment questions at the individual and organisational levels of resource allocation (Michaelis and Schwaneback, 2016). In respect to the former, how much time do students take to prepare for different types of assessment (e.g., formative vs. summative)? What is the optimal strategy in allocating time between formative and summative assessments preparation? How do institutional processes (e.g., re-sits, repeating a year) influence student assessment behaviour? How is innovation in assessment developed and implemented, for example the use of computerised adaptive testing as either a formative or summative activity? In respect to organisational level of resource allocation, how many OSCE stations are optimal given each station will have a cost (e.g., examiner time, an actor or simulated patient, consumables, refreshments, room hire)? Is the investment of staff training and quality assurance processes required to score short-answer questions (SAQs) considered worthwhile? Or do medical schools take a more satisficing approach, appreciating that some aspects of their assessment are not optimal but the best they can do within resource limits.

There are many other aspects of education we could consider through an economic lens. The relatively new phenomena of micro-credentialing, for example, can be considered in terms of optimization from both the learner perspective (just enough learning for professional recognition, achievable in terms of motivation, cost and time) and that of the provider (a new pool of consumers, efficient use of existing resources, extending brand recognition and an alternative pathway for study in award or other courses) (e.g., Young, West and Nylin 2019).

Another relevant area is curricular innovation and reform. Using an economic lens, the ultimate goal of curriculum reform can be considered as optimizing the curriculum in some way (e.g., removing lectures and investing in online resources to free up previous didactic time for more interactive face to face teaching and learning). Drawing on evidence from healthcare, this optimization is likely to be linked to abundance or scarcity of resources. Scarcity promotes adoption of innovations that enhance efficiency, whereas availability of resources promotes advanced, expensive innovations (e.g., Lambooij, Engelfriet and Westert 2010). The context (societal structures and characteristics, including the macroeconomic environment, level of regulation, expectations and norms, and so on) in which HPE operates and, at an individual level, faculty and student perceptions and attitudes, including self-interest (e.g., wishing to protect curriculum time for one's own subject), will also act as bounds in terms of both the problems faced and the decisions that are made in terms of change. Consider educational responses to the Covid-19 pandemic in 2020. Social distancing and infection control measures limited access to clinical and campus environments overnight (scarcity) and HPE providers rapidly shifted to online and digital learning (efficiency), where they had the systems and resources to do so (Cleland et al. 2020). 


\section{Conclusions}

In conclusion, as per Jagger and Richards, You can't always get what you want. But if you try sometimes, well, you just might find you get what you need. Aspects of individual, group and institutional decision making in HPE may sometimes seem less than rational on the surface but make sense when considered using the concepts of scarcity, optimization and bounded rationality. Embracing economic thinking opens up new questions and new ways of approaching old questions which can add knowledge about how choice is enacted in contemporary health professions education.

Acknowledgements Our thanks to Robert Golub and David Cook, also SCVHPE members, for their encouragement when we were considering the shape of this paper.

Authors contribution JC suggested and coordinated this collaborative effort, helped create and revise outlines and drafts, and contributed significantly to the intellectual contents. MYY helped create and revise outlines and drafts and contributed significantly to the intellectual contents. JF, SM and DI contributed to the intellectual contents and critically reviewed drafts. All authors gave approval of the version to be published and agree to be accountable for the work.

Funding We did not seek external funding for this project.

\section{Compliance with ethical standards}

Conflict of Interest The authors are all members of the Society for Cost and Value in Healthcare Professions Education (SCVHPE: https://www.monash.edu/medicine/sphpm/units/scvhpe), the aim of which is to develop capacity for evidence-based decision making concerning the cost and value of health professions education.

Ethical approval Not applicable as human or animal subjects were not involved in the creation of this contribution.

\section{References}

Arrow, K. (2004). Is bounded rationality unboundedly rational? Some ruminations. In M. Augier \& J. G. March (Eds.), Models of a man: Essays in memory of Herbert A. Simon (pp. 47-55). Cambridge: MIT Press.

Association of American Medical Colleges. (2017). An updated look at attendance cost and medical student debt at U.S. medical schools. Retrieved June 29, 2020, from https://www.aamc.org/system/ files/reports/1/august2017anupdatedlookatattendancecostandmedicalstudentdebtatu.pdf.

Bacher-Hicks, A., Chin, M. J., Kan, T. J., \& Staiger, D. O. (2019). An experimental evaluation of three teacher quality measures: Value-added, classroom observations and student surveys. Economics of Education Review, 73, 101919.

Backhouse, R. E. (2002). The Penguin history of economics. London: The Penguin Group.

Backhouse, R. E., \& Tribe, K. (2018). The history of economics: A course for students and teachers. London: Agenda Publishing.

Brewer, D. J., Hentschke, G. C., \& Eide, E. R. (2010). Theoretical concepts in the economics of education. In P. Peterson, E. Baker, \& B. McGaw (Eds.), The international encyclopedia of education (pp. 193-198). Amsterdam: Elsevier Ltd.

Brown, C., Ross, S., Cleland, J. A., \& Walsh, K. (2015). Money makes the (medical assessment) world go round: The cost of components of a summative final year Objective Structured Clinical Examination (OSCE). Medical Teacher, 37, 653-659.

Burki, T. K. (2020). COVID-19: Consequences for higher education. The Lancet Oncology, 21(6), 758. 
Cleland, J. A., Hanson, M., \& Patterson, F. (2018a). Thinking of selection and widening access as complex and wicked problems. Medical Education, 52(12), 1228-1239.

Cleland, J. A., Johnston, P., Watson, V., Krucien, N., \& Skatun, D. (2016). What do UK doctors-intraining value in a post? A discrete choice experiment. Medical Education, 50(2), 189-202.

Cleland, J. A., Johnston, P., Watson, V., Krucien, N., \& Skatun, D. (2017). What do UK medical students value most in their career? A discrete choice experiment. Medical Education, 51, 839-851.

Cleland, J. A., Porteous, T., \& Skatun, D. (2018b). What can discrete choice experiments do for you? Medical Education, 52, 1113-1124.

Cleland, J., McKimm, J., Fuller, R., Taylor, D., Janczukowicz, J., \& Gibbs, T. (2020). Adapting to the impact of COVID-19: Sharing stories, sharing practice. Medical Teacher. https://doi. org/10.1080/0142159X.2020.1757635

Currie, G. P., Sivasubramaniam, S., \& Cleland, J. A. (2016). Sequential testing in a high stakes OSCE: Determining number of screening tests. Medical Teacher, 38, 708-714.

Dawnay, E., \& Shah, H. (2005). Behavioural economics: Seven principles for policy-makers. London: New Economics Foundation.

DeVroey, M. (1975). The transition from classical to neoclassical economics: A scientific revolution. Journal of Economic Issues, 9(3), 415-439.

Fielding, S., Tiffin, P. A., Greatrix, R., Lee, A. J., Patterson, F., Nicholson, S., et al. (2018). Do changing medical admissions practices in the UK impact on who is admitted? An interrupted time series analysis. BMJ Open, 8, e023274. https://doi.org/10.1136/bmjopen-2018-023274

Foo, J., Cook, D. A., Walsh, K., Golub, R., Abdalla, M. E., Ilic, D., et al. (2019). Cost evaluations in health professions education: A systematic review of methods and reporting quality. Medical Education, 53(12), 1196-1208.

Foo, J., Cook, D. A., Tolsgaard, M., Rivers, G., Cleland, J., Walsh, K., et al. (in press). AMEE Guide 139: How to conduct cost and value analyses in health professions education.

Foo, J., \& Hay, M. (2020). Designing for value in medical residency selection. Medical Education. https ://doi.org/10.1111/medu.14290.

Foo, J., Rivers, G., Allen, L., Ilic, D., Maloney, S., \& Hay, M. (2020). The economic costs of selecting medical students: An Australian case study. Medical Education, 54, 643-651.

Furubotn, E., \& Richter, R. (2003). Institutions and economic theory: The contributionof the new institutional economics. Ann Arbor: University of Michigan Press.

Halpern, M. T., Luce, B. R., Brown, R. E., \& Geneste, D. (1998). Health and economic outcomes modeling practices: A suggested framework. Value in Health, 1(2), 131-147.

Hessler, M., Pöpping, D. M., Hollstein, H., Ohlenburg, H., Arnemann, P. H., Massoth, C., et al. (2018). Availability of cookies during an academic course session affects evaluation of teaching. Medical Education, 52, 1064-1072.

Hissbach, J. C., Sehner, S., Harendza, S., \& Hampe, W. (2014). Cutting costs of multiple mini-interviews - Changes in reliability and efficiency of the Hamburg medical school admission test between two applications. BMC Medical Education, 14, 54. https://doi.org/10.1186/1472-6920-14-54.

Horstchraer, J. (2012). University rankings in action? The importance of rankings and an excellence competition for university choice of high-ability students. Economics of Education Review, 31, 1162-1176.

Johnes, G. (1993). The economics of education. Basingstoke: Macmillan.

Keynes, J. M. (1921). A treatise on probability. New York: Dover Publications.

Keynes, J. M. (1936). The General Theory of Employment, Interest, and Money. New York: Palgrave MacMillan.

Lambooij, M. S., Engelfriet, P., \& Westert, G. P. (2010). Diffusion of innovations in health care: Does the structural context determine its direction? International Journal of Technology Assessment in Health Care, 26(4), 415-420.

Lenton, P. (2015). Determining student satisfaction: An economic analysis of the national student survey. Economics of Education Review, 47, 118-127.

Maloney, D. A., Cook, D., Golub, R., Foo, J., Cleland, J., Rivers, G., et al. (2019). AMEE guide no. 123-How to read studies of educational costs. Medical Teacher, 41(5), 497-504.

Mankiw, N. G. (2011). Principles of economics (6th ed.). Mason: South-Western Cengage Learning.

McCormack, J., Propper, C., \& Smith, S. (2014). Herding Cats? Management and University Performance. The Economic Journal, 124, 534-564.

Meek, R. L. (1977). Smith, Marx \& after: Ten essays in the development of economic thought. London: Chapman \& Hall).

Michaelis, J., \& Schwanebeck, B. (2016). Examination rules and student effort. Economics Letters, 145, 65-68. 
Murray, J. B., \& Evers, D. J. (1989). Theory borrowing and reflectivity in interdisciplinary fields. In T. A. In \& Srull (Eds.), Advances in Consumer Research (Vol. 16, pp. 647-652). Provo: Association for Consumer Research).

Nielsen, P. A., \& Moynihan, D. P. (2017). How do politicians attribute bureaucratic responsibility for performance? Negativity bias and interest group advocacy. Journal of Public Administration Research and Theory, 27(2), 269-283.

Patterson, F., Knight, A., Dowell, J., Nicholson, S., \& Cleland, J. A. (2016). How effective are selection methods in medical education?\&nbsp;A systematic review. Medical Education, 2016(50), 36-60.

Scanlan, G., Cleland, J. A., Johnston, P. J., Walker, K., Krucien, N., \& Skatun, D. (2018). Location and support are critical to attracting junior doctors: A discrete choice experiment. British Medical Journal Open, 8(3), e019911. https://doi.org/10.1136/bmjopen-2017-019911.

Schreurs, S., Cleland, J., Muijtjens, A. M. M., oude Egbrink, M. G. A., \& Cleutjens, K. (2018). Does selection pay off? A cost-benefit comparison for medical school selection and lottery systems. Medical Education, 52, 1240-1248.

Self, C. C. (2009). Credibility. In (In D. W. Stacks \& M. B. Salwen (Eds.), An integrated approach to communication theory and research (2nd ed., pp. 435-456). New York: Routledge.

Simon, H. A. (1955). A behavioural model of rational choice. Quarterly Journal of Economics, 69(1), 99-118.

Simon, H. A. (1957). Models of Man. New York: John Wiley.

Skinner, A. S. (2003). Adam Smith (1723-1790): Theories of political economy. In (In W. J. Samuels, J. E. Biddle \& J. B. Davis (Eds.), A companion to the history of economic thought (pp. 94-111). Oxford: Blackwell Publishing.

Smith, A. (1776). An Inquiry into the Nature and Causes of the Wealth of Nations. Now in its 18th Edition, as Smith, A. \& Cannan, E. (2003). The Wealth of Nations. (New York, N.Y: Bantam Classic).

Staddon, E., \& Standish, P. (2012). Improving the student experience. Journal of the Philosophy of Education, 46(4), 631-648.

Stamovlasis, D., \& Vaiopoulou, J. (2017). The role of dysfunctional myths in a decision-making process under bounded rationality: A complex dynamical systems perspective. Nonlinear Dynamics, Psychology and Life Science, 21(3), 267-288.

Roncaglia, A. (2005). The wealth of ideas: A history of economic thought. Cambridge: Cambridge University Press.

Rosenfeld, J. M., Reiter, H. I., Trinh, K., \& Eva, K. W. (2008). m A cost efficiency comparison between the multiple mini-interview and traditional admissions interviews. Advances in Health Sciences Education, 13, 43-58.

Thaler, R. H., \& Sunstein, C. R. (2009). Nudge: Improving decisions about health, wealth and happiness. London: Penguin.

Tiller, D., O’Mara, D., Rothnie, I., Dunn, S., Lee, L., \& Roberts, C. (2013). Internet-based multiple miniinterviews for candidate selection for graduate entry programmes. Medical Education, 47, 801-810.

Tolsgaard, M., Cleland, J., Wilkinson, T., \& Ellaway, R. (2020). How we make choices and sacrifices in medical education during the COVID-19 pandemic. Medical Teacher (In press).

Varpio, L., Martimianakis, M. A., \& Mylopoulos, M. (2015). Qualitative research methodologies: Embracing methodological borrowing, shifting and importing. In J. A. Cleland \& S. J. Durning (Eds.), Researching medical education (pp. 245-255). Oxford: Wiley.

Walsh, K. (2014). Medical education: Microeconomics or macroeconomics? The Pan African Medical Journal, 18 (11), https://doi.org/10.11604/pamj.2014.18.11.4334.

Whitehead, C. R. (2011). The good doctor in medical education 1910-2010: A critical discourse analysis. Dissertation, University of Toronto. Accessed 14 October 2020.

Young, D., West, R. E., \& Nylin, T. A. (2019). Value of open microcredentials to earners and issuers: A case study of national instruments open badges. International Review of Research in Open \& Distance Learning, 20(5), 105-121.

Ziv, A., Rubin, O., Moshinsky, A., Gafni, N., Kotler, M., Dagan, Y., et al. (2008). MOR: A simulation-based assessment centre for evaluating the personal and interpersonal qualities of medical school candidates. Medical Education, 42, 991-998.

Publisher's Note Springer Nature remains neutral with regard to jurisdictional claims in published maps and institutional affiliations. 